\title{
PILOT TRIAL RESULTS IN ASSESSING ENGLISH UTERACY OF APPLICANTS TO MEDICAL RESIDENCIES.
}

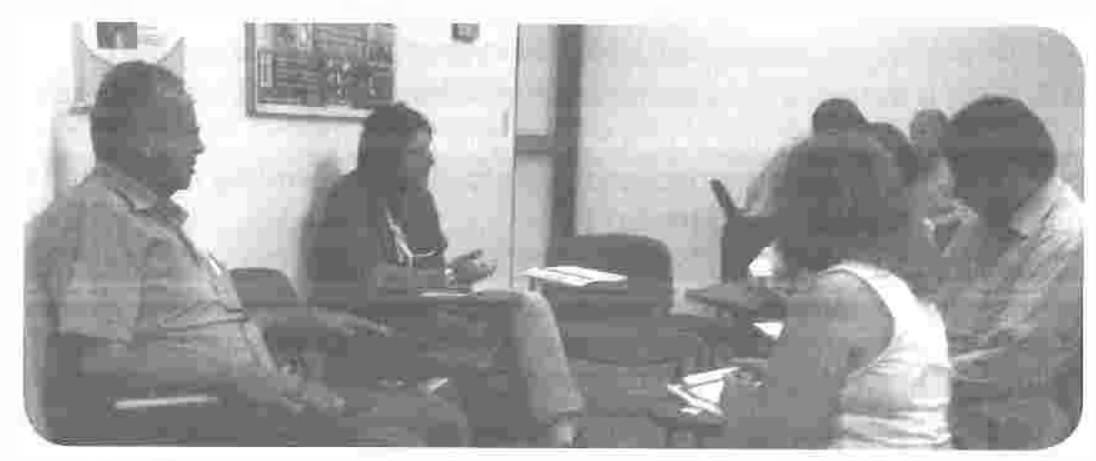

Authors: Dr. Sanabria Rivera L.E. General Surgeon and Director of Medicine's Program at Surcolombiana university. Dr. Polo Ledezma R. E. Teacher of Biochemistry at Surcolombiana university-remipole@gmail.com

Dr. Ramírez CuellarT. A. Head and Neck's Surgeon and Teacher of General Surgery and Clinical Epidemiology at Surcolombiana university.

\section{ABSTRACT.}

PACA Research Group.

Objective. The main goal of this paper is to statistically describe the results obtained by 355 applicants to medical residencies, after responding a technical English test with 24 exercises. Justification. English is indispensable for reading, understanding specialized medical texts, for listening podcasts with the last scientific and technological advances in Medicine, and for writing and communicating medical reports.

Main Results. From 355 applicants to medical residency only seven have the necessary competences in Medical English to be a postgraduate student. The majority of aspirants have problems related with bad english competences in the act of correct managing of verb tenses, medical vocabulary, semantics and English syntax.

\section{INTRODUCTION}

Medical doctors, and in general, all people working at the health sector, daily need understand several topics for which it is very impossible to meet good believable information in Spanish. They must search periodical publications, and read english technical papers, or listen podcasts or audio-files edited in that language.

In Colombia although physicians very like to speak about their daily successful experiences with patients, they can not publish them in high impact international journals because 
editors of several periodical publications do not accept english writings with big textual mistakes. Between the most frequently ones found in those papers are the bad uses of verbs tenses, the incorrect grammatical building of english phrases, big troubles in vocabulary using grammatical terms such as prepositions, idioms, adverbs, affixes, and articles (1).

Technical English is essential for obtaining information related with the last advances in medical research, the new technical procedures, and the incoming of fresh most powerful technologies. That language is also indispensable for listening, writing and communicating reports related with the practice of medicine.

Many recent studies, around the world, have focused on problems related with the bad use of technical English by people who do not born in places where this language is the first one essential $(2,3,4,5,6)$.

Although in several subjects such as Biochemistry, Immunology, Genetics, Biology, and Pathology students read english papers and books, the curricular plan of Health's Faculty at 5 urcolombiana university do not offer special courses for learning technical english (7). For this reason using a sample we have decided to comparatively study what are the true english competences of physicians who egress of medical institutions in Colombia.

At the end of each year, the postgraduate staff of our medical institution make the compulsory examination for selecting the physicians who will enter to occupy places as residents in the most basic specialties. As requisite aspirants must answer a questionnaire, where they meet a set of questions to test their knowledge in medical english (7). The goal of our study was to use data produced, by the 2013 year applicants, after responding that english test to know better what are their true aptitudes and abilities in technical english. The main purpose of this paper is to report the results obtained in the convocation done by the medical postgraduate council of the Health's faculty in the Surcolombiana university, at the end of 2013 year, after collecting, organizing, and analyzing those data, using the free software $R$ environment for statistical computing and obtaining graphics.

METHODOLOGY.

We studied the results obtained in a compulsory examination by 355 applicants egressed from 40 Colombian universities and from ten institutions of higher education located in Ecuador and Cuba. Because at first they must answer a very long set of questions for evaluating their practical clinical knowledge, they do not have much time for being correctly evaluated in Medical English. That examination focus on applicant's capacity to analyze, reason effectively to solve and interpret problems in a variety of clinical situations. We decided to evaluate them by an easy careful study of their abilities for solving very general exercises, which contain the most important subjects used in English medical papers.

They answered in 30 minutes a special designed by us questionnaire, which contains 24 exercises. The form is divided into five parts, each one of them has a format that is simple and easy to understand; it contains exercises to evaluate a specific topic of this language. The competencies assessed were: Verb Phrases, Vocabulary, Structure of English Sentences, Medical Knowledge and English Editing. 
The final obtained grades were introduced to the local disk of a computer which contains the free open online statistical software $R$. We used the $R-3.0 .2$ version for windows operating system. Descriptions and data analysis were made by the classical deductive procedure used in traditional statistics which includes the calculation of averages, measures of central tendency and dispersion, the obtaining of box plots, histograms, graphs of distribution, and several other plots, which can be used for drawing valid conclusions and inference.

\section{RESULTS.}

Table one shows the numbers of applicants egressed from several Colombian and foreign universities. As we can see the majority of them were physicians from the Surcolombiana university. A big fraction of aspirants were egressed from Tolima's university and the San Martin college foundation.

Table 1

\begin{tabular}{|l|c|c|c|c|c|c|}
\hline Institution & L.M. & Ped. & G.O. & Sur. & A.R. & Total \\
\hline Surcolombiana University. & 32 & 27 & 17 & 13 & 20 & 109 \\
\hline Tolima University. & 14 & 5 & 5 & 4 & 6 & 34 \\
\hline San Martín College Foundation. & 7 & 5 & 3 & 3 & 8 & $\mathbf{2 6}$ \\
\hline National University. & 5 & 5 & - & 3 & 4 & 17 \\
\hline Rafael Núñez College Corporation. & 4 & 2 & 1 & - & 5 & $\mathbf{1 2}$ \\
\hline Antonio Nariño University. & 3 & 6 & - & 1 & 1 & $\mathbf{1 1}$ \\
\hline Manizales University. & 2 & 3 & 2 & 1 & 2 & 10 \\
\hline Corpas University. & 3 & 3 & 1 & 1 & 2 & $\mathbf{1 0}$ \\
\hline CUBA. & 3 & 1 & 1 & - & - & $\mathbf{5}$ \\
\hline ECUADOR. & 1 & 1 & 1 & - & 2 & $\mathbf{5}$ \\
\hline Don't Respond. & 9 & - & 3 & - & 7 & $\mathbf{1 9}$ \\
\hline Other Universities. & 19 & 21 & 20 & 10 & 27 & $\mathbf{9 7}$ \\
\hline Total & $\mathbf{1 0 2}$ & $\mathbf{7 9}$ & $\mathbf{5 4}$ & $\mathbf{3 6}$ & $\mathbf{8 4}$ & $\mathbf{3 5 5}$ \\
\hline
\end{tabular}

As we can see in this table the number of applicants by specialty were: 102 to Internal Medicine residency (IM.), 36 to Surgery (Sur.), 79 were interested in Pediatrics (Ped), 54 in Gynecology-Obstetrics (G.O.), and 84 to Anesthesiology (A.R.).

The questionnaire has a total value of 24 points. Its score approval is 15. Figure one (Fig 1) shows the histogram corresponding to the absolute frequency distribution of the final grades in Medical english of 355 applicants. Each bar area is proportional to frequency of aspirants, so the total area of histogram is the total number of applicants. 
Fig.1 G2 Compilado Total 355 Aspirantes 2013B

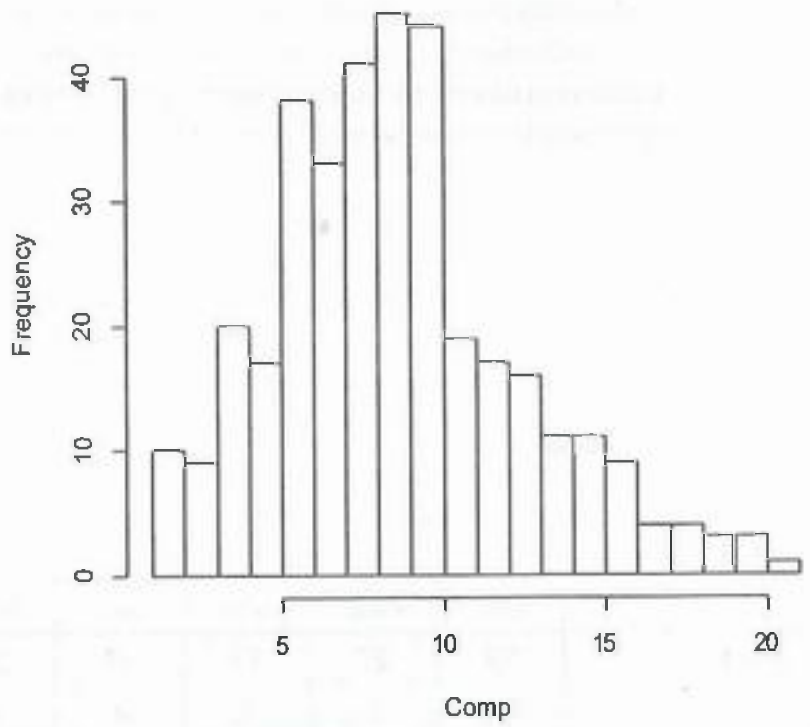

Fig 2 is the plot density that corresponds to that histogram. Applicants obtained grades between one and 21 (only one physician). The ten lowest ranking aspirants made correctly only one exercise. Twenty four applicants received grades higher than 15. It means that they approved the English examination. One hundred and ninety nine aspirants received grades higher than 5 but lower than 10. Fifty seven had grades not higher than 5 .

Fig. 2 density.default $(x=$ Comp $)$

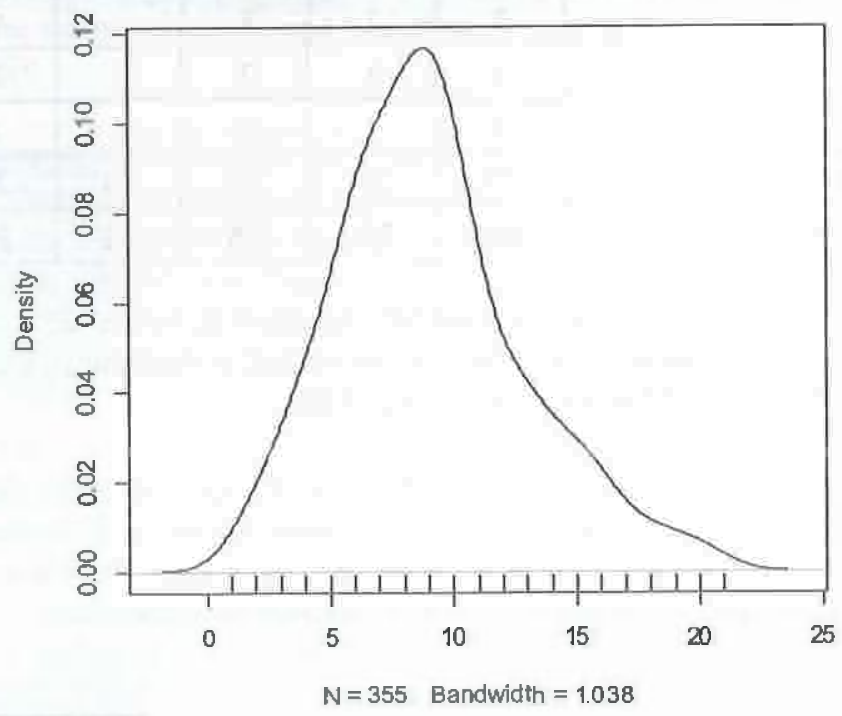


Table two shows the mean, median, standard deviation and other measures of central tendency for the studied sample of applicants (Comp).

\title{
Table2
}

\author{
summary(Comp) \\ Min.1st Qu. Median Mean 3rd Qu. Max. \\ $\begin{array}{llll}1.000 & 6.000 \quad 9.000 \quad 9.025 & 1.000 \quad 21.000\end{array}$ \\ sd(Comp) 3.817434
}

Fig 3 is a box plot which clearly describes a sample moderately asymmetrical, skewed to the right, although with a high tendency to give a graph with a classical bell shaped Gaussian form. This aspect may be corroborated by the profile of the Q-Q graphic (Fig 4.) and by the obtained nearly similar mean and median values.

Fig.3 G 1 Compilado Total 355 Aspirantes - 2013B

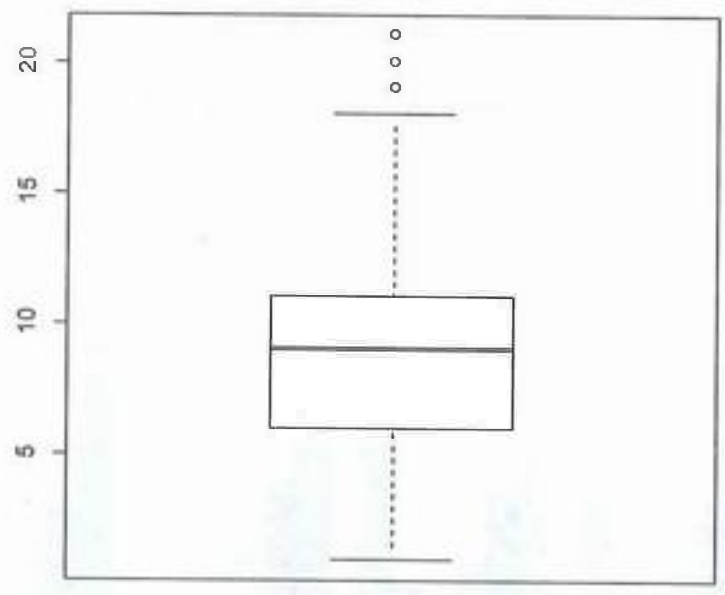

Fig-4 Normal aq Plot

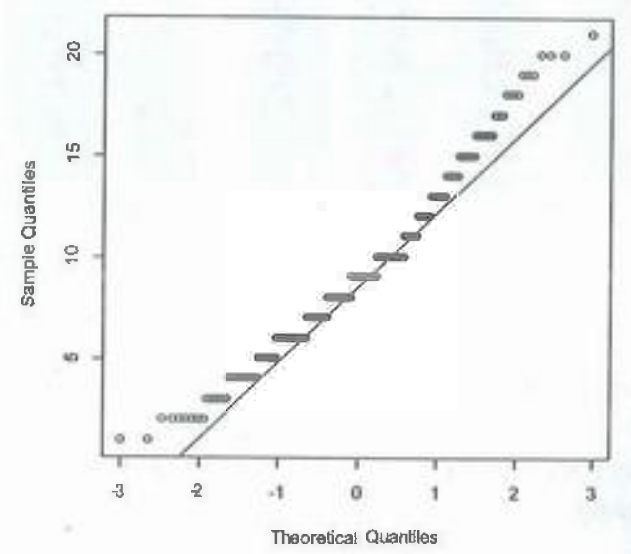


The $z$ statistics for 15 was 1,565 a value that corresponds to an approving percentage close to6\%.

Fig 5. is a chart called for us the qualifygram by specialties. It is a vertical bar graph where each one shows as percentage of the total maximum grade the results obtained by all applicants of each specialty. For each field there are six vertical bars. The first one corresponds to the total collective grade in competence of correct using verbs tenses. The second one presents the score in percentage obtained by all applicants of each specialty in exercises designed for evaluating the competences in vocabulary or lexicon. The third one corresponds to proficiency levels in building English sentences. The fourth shows the ability of applicants for answering questions, using the correct grammatical forms in sentences related with medical knowledge. The last but one bar shows in percentage the collective capacity for editing and using correct words in English texts. The sixth bar corresponds to the corresponding total cumulative results.

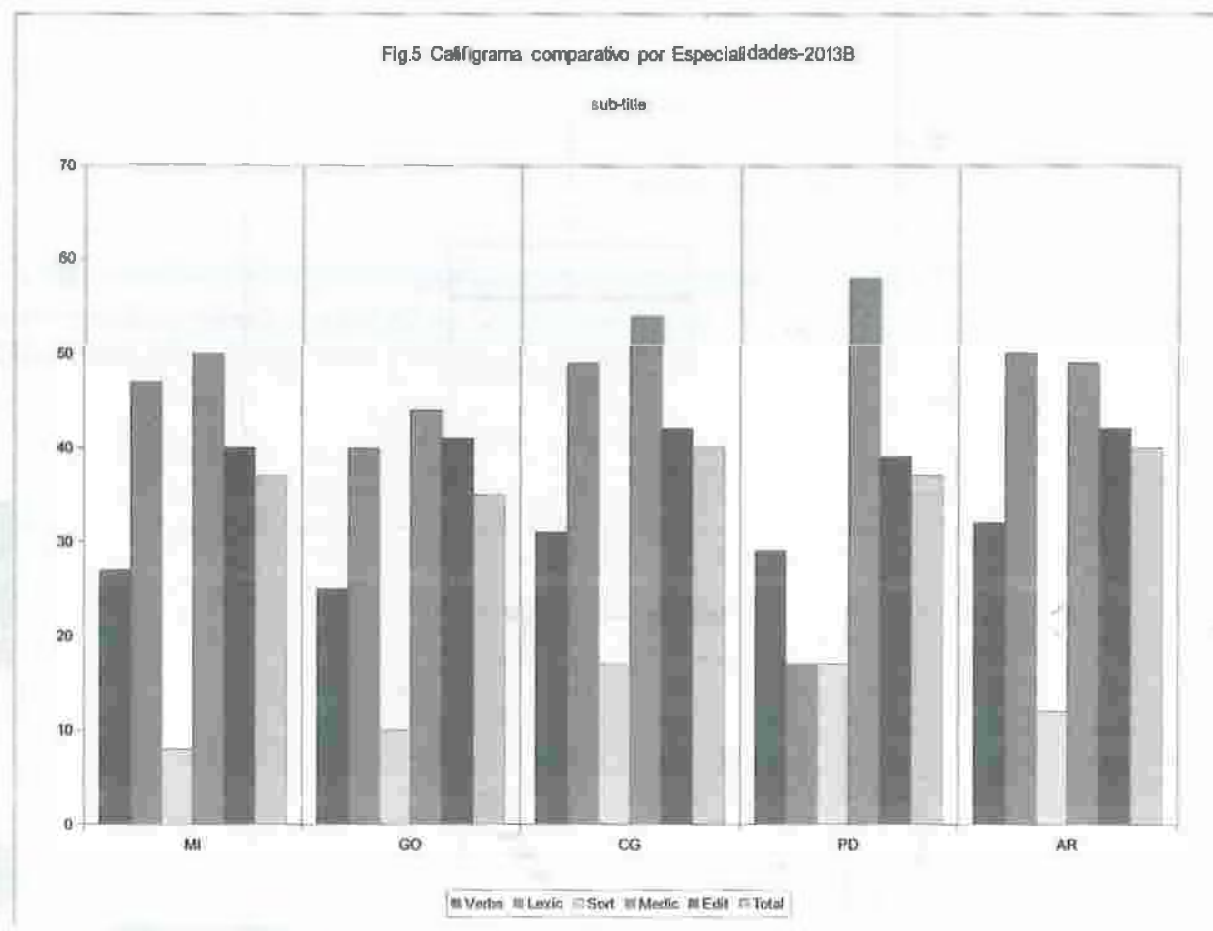

Fig 6 is a comparative bar graph which shows in percentages the qualification of all applicants by specialty. The first vertical rectangle corresponds to aspirants qualified relatively as excellents. The remaining bars correspond to those with qualification of acceptable, regular, bad, and worse respectively. 


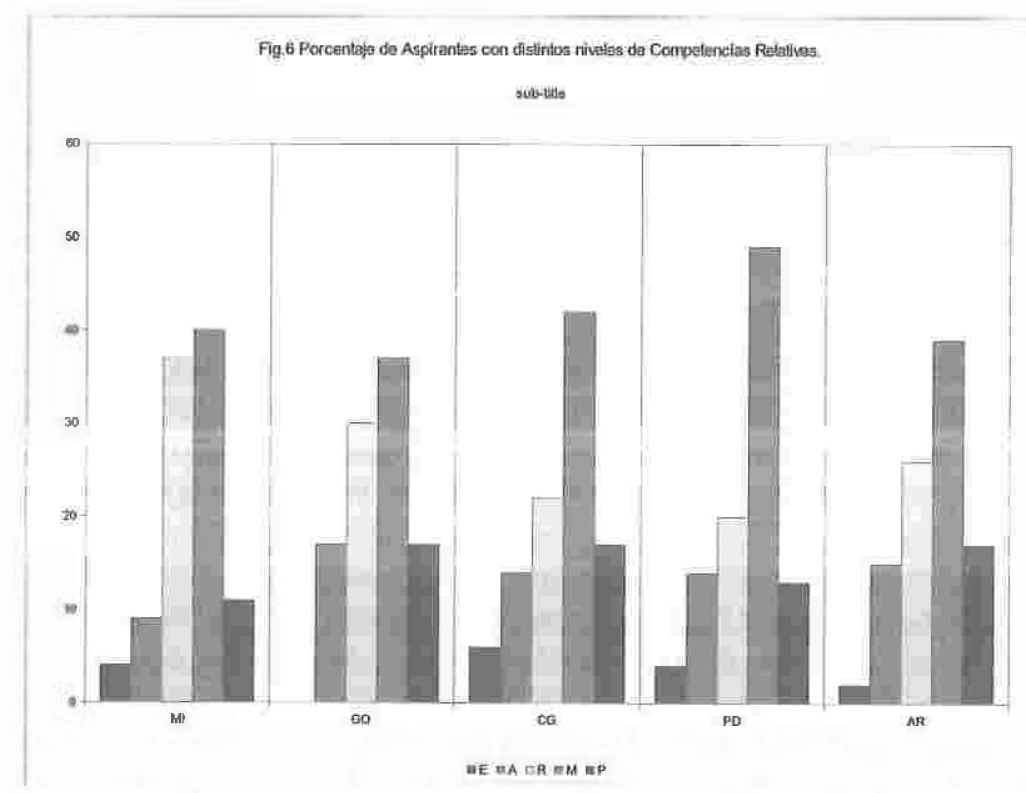

Fig 7 is a bar graph similar to that one drawn on figure 5; the only difference is that in this case we compare the total collective results produced by applicants egressed from Surcolombiana, Tolima universities and SanMartín college foundation.

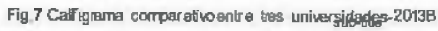

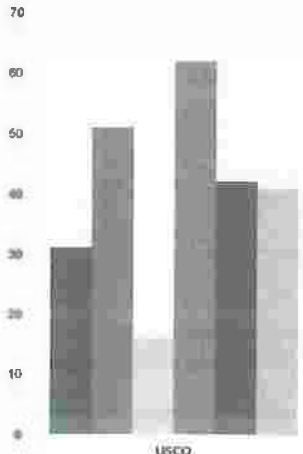

usco

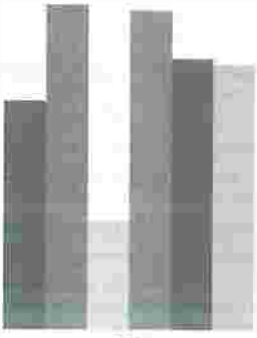

TOI.

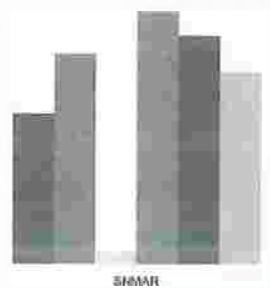




\section{DISCUSIÓN.}

321 applicants obtained a low grade on the examination in Medical English. The mean was 9,025 and the standard deviation was $42,3 \%$. It points out that we had a quite heterogeneous group in terms of their competences. The D1, D2, D4, D6, and D8, were $4 ; 6 ; 8 ; 9,4$; and 12 respectively. The median was nine. Thus $80 \%$ of the applicants obtained 12 or less points from 24 possible. The box plot in Fig 3 shows that the three white points above the graph correspond to 7 applicants who approved the Medical English examination and obtained the highest scores are significantly very different to the others 348 . This highly significative difference seems to indicate radical differences in individual Medical English competences. All of those seven aspirants answered very well the exercises with verb phrases, vocabulary and sorted well the words for correctly writing sentences in Medical English.

In Fig 5 the last bar shows that the yield average of applicants never was higher than $40 \%$ and oscillated between 30 and $40 \%$. This may be associated with the bad use and understanding of grammatical forms in our native language. In Spanish we do not use correctly the perfect and the progressive or continuous tenses of verbs. Some Colombian people can not express events or actions in term of a specific verb tense. It is interesting to note that the majority of applicants can not sort correctly the sentences given them the corresponding words.

The program made by us in $R$ allows to calculate the $z$ standard for each applicant, and with that value we obtained a competence's index in Medical English for each aspirant. The software compared the results of each of the applicants with the sample's average value, calculated how many times was higher that difference in relation to the standard deviation and classified them, by their efficacy, in five groups accordingly their relative Medical English proficiency levels in: excellent, acceptable, regular, bad and worst applicants. This classification is shown in table 3. Each group indicates the relative ability that has an applicant to respond successf ully to the exercises of the proposed contextual questionnaire.

Table3

\begin{tabular}{|c|c|c|}
\hline Qualification & Competence's Index Range & Initial \\
\hline Excellent. & $\mathrm{C} . \mathrm{L} .>2$ & $\mathrm{E}$ \\
\hline Acceptable. & $2>=\mathrm{CI} .>1$ & $\mathrm{~A}$ \\
\hline Regular. & $1>=\mathrm{CII}>$ & $\mathrm{R}$ \\
\hline Bad. & $0>=\mathrm{C} . \mathrm{I} .>$ & $\mathrm{B}$ \\
\hline Worse. & $-1>=\mathrm{C.I}$. & $\mathrm{W}$ \\
\hline
\end{tabular}

An excellent applicant is eminently good in relation with the others. An acceptable is relatively well respect to the scores obtained by the rest. A regular aspirant has competences in Medical English relatively similar to those of an average applicant. Fig 6 shows that in all groups of applicants the majority were regular, bad, and worse in Medical English. 
Taking into account that scores obtained by the majority of applicants were very low we consider that only should be admitted those who were classified as excellents by the software R. Bad or worse applicants do not have the indispen sable Medical English competences for being a physician serving a clinical residency. A resident needs to have a good knowledge and skills in that language for correct reading, understanding, and interpreting well texts published in specialized journals, magazines, books. He must listen and understand very well, english podcasts and videos related with his specialty. Applicants from acceptable and regular groups must be capacitated in Medical English.

The profile of the comparative qualifygram by specialty (Fig 5) shows no significant differences in the level of skills of the groups. It is interesting to note that those interested in Pediatrics although scored much lower in vocabulary in relation to applicants of other specialties. They obtained better results on the proposal exercises for evaluating competences in English semantics, necessary for reading and understanding medical texts. The applicants to Internal Medicine showed to have more problems related with English syntax in aspects related with the harmonious arrangement of words in phrases and english sentences.

The vertical bar graph in figure 7 shows for the Surcolombiana andTolima universities scores consistently higher than those obtained by the applicants of San Martin college foundation. Aspirants egressed of this last institution scored between 6 to $20 \%$ below in relation with their similar of other mentioned above universities. This difference may be related with the heterogeneous professional profile that have egressed from those institutions $(8,9)$. The San Martin curricular plan is most focused to the formation of a professional strong in clinical patient assistance and medical care (9), while in Tolima and Surcolombiana universities the courses offered are focused to medical clinical research and basic investigation (8).

It is very difficult to judge the quality of English educational system in Colombia against a single and simple assessment. Although our test was well designed and provide good data related with competences in English knowledge, there is much that we do not assessed. It is a|so impossible to set future goals based on our results, but we consider that if universities improve theirenglish educational system they will improve the applicants outcomes in those annual tests of medical proficiency.

\section{REFERENCES.}

1. Durand V.N. Loe I.M. Yeatman J.D. Feldman H. M. Effects of early language, speech, and cognition on later reading: a mediation analysis. Frontiers in Psychology. 2013; 4: 586.

2. Elaine YL. Sadia M Malick, Khalid S Khan. On-the-Job Evidence-Based Medicine Training for Clinician-Scientists of the Next Generation. Clinical Biochemist Reviews. 2013 August; 34(2): $93-103$.

3. Mohsen Rezaeian. How to teach medical students to critically appraise a published artide in the public health domain. Journal of Education and Health Promotion. 2013; 28. 
4. Kabacoff C. Srivastava V. Robinson D.N. A Summer Academic Research Experience for Disadvantaged Youth. CBE Life Sciences Education. 2013 Fall; 12(3): 410-418.

5. John M. An A to Z for peer writing. HSR Proceedings Intensive Care Cardiovascular Anesthesia. 2013; 5(2): 122-123.

6. Marambe K.N. Edussuriya D.H. Dayaratne K.M.P.L. Attitudes of Sri Lankan Medical Students toward Learning Communication Skills. Education for Health. 2012; 25(3): 165-171.

7. Programa de Medicina de la Facultad de Salud de la Universidad Surcolombiana. http// www.usco.edu.co/pagina/medicina.

8. Programa de Medicina de a Facultad de Ciencias de $\mathbf{a}$ Salud de la Universidad delTolima. http://desarrollo.ut.ed u.co/tolima/ hermesoft/portal/home_1/htm/conto.jsp?rec=not_14359.jsp

9. Facultad de Medicina de la Fundación Universitaria San Martín. http://www.sanmartin.edu.co/academicos_new/medicina/index.php 